\title{
Trabalho e práticas sociais das mulheres: encontros entre a sociologia das relações sociais de sexo e a psicodinâmica do trabalho
}

Thaís de Souza Lapa ${ }^{1}$

\section{Resumo}

Desenvolvo neste artigo um debate sobre condições de trabalho e práticas sociais de trabalhadoras, que são compreendidas ao mesmo tempo como parte das relações sociais de sexo e de classe. Com base em contribuições, sobretudo francófonas, acerca da psicodinâmica e da divisão sexual do trabalho, procurarei desenvolver aspectos do debate teórico sobre o sofrimento e a construção de « estratégias coletivas de defesa das mulheres no trabalho. 0 texto é desenvolvido procurando identificar e trabalhar conceitos heuristicamente úteis para a análise das condições de trabalho e das práticas sociais delas derivadas, oriundos dos campos teóricos da psicodinâmica do trabalho e da sociologia das relações sociais de sexo, a exemplo dos conceitos de virilidade e feminilidade socialmente construídas. Também pretende-se recuperar parte das contribuições mútuas entre esses dois campos teóricos.

\section{Palavras-chave}

Práticas sociais no trabalho. Mulheres trabalhadoras. Subjetividade e trabalho.

\begin{abstract}
In this article I develop a debate about female workers' work conditions and their social practices, both understood as part of gender and class relations. Based mostly on French contributions, concerning the work psychodynamics and the sexual division of labor, I seek to develop aspects of the theoretical debate related to suffering and the construction of women's "collective strategies of defense" in the workplace. The text is developed trying to identify and discuss concepts heuristically useful to the analysis of work conditions and the social practices derived from them, which proceeds from the work psychodynamics and sex social relations sociology theoretical fields, discussing, for example, the socially constructed masculinity and femininity. Finally, the article aims to recover part of the mutual contributions between these two theoretical fields.
\end{abstract}

\section{Keywords}

Workers' social practices. Female workers. Subjectivity and work.

\footnotetext{
${ }^{1}$ Doutora em Ciências Sociais pela Universidade Estadual de Campinas (ÚNICAMP), professora adjunta do Departamento de Sociologia e Ciência Política da Universidade Federal de Santa Catarina (UFSC). E-mail: thais_lapa@yahoo.com.br.
} 


\section{Introdução}

Analisar condições de trabalho levando em consideração as relações sociais de gênero constitui uma abordagem crucial para se compreender as desigualdades que derivam de diferenças sexuadas nos espaços de trabalho. Ao mesmo tempo, pode ser também um campo de reflexões que identifica situações como estanques e cristalizadas. Explico: ao reconhecer que, por exemplo, sob muitas óticas de análise e em vários setores profissionais as mulheres realizam trabalhos mais precários e menos valorizados que os dos homens, retrata-se uma situação que, embora real, é mostrada mais como uma fotografia que como um vídeo - como um dado mais do que como um processo.

Neste texto, procuro recuperar a dinamicidade que envolve as condições de trabalho das mulheres a partir da recuperação de debates que observam trabalhadores/as não somente como "afetados/as" por determinadas condições de trabalho, mas como capazes de reelaborar as condições dadas - o que conduz a um debate sobre a conformação de suas práticas no trabalho.

As análises que embasam este texto (DEJOURS, 1993, 2012; HIRATA; KERGOAT, 2002 [1988]; MOLINIER, 2013, entre outras) abordam a relação entre condições de trabalho, saúde e subjetividade e desenvolvem, justamente, não somente caracterizações das condições de trabalho a partir do "real do trabalho", mas também a problemática da construção de estratégias coletivas de defesa. Tal formulação erige do referencial da psicodinâmica do trabalho, mas chegou a ser desenvolvido também a partir da sociologia das relações sociais de sexo.

O aporte da psicodinâmica do trabalho sobre o campo é original ao não se focar propriamente nas formas de adoecimento, nas doenças decorrentes da organização do trabalho, mas em questionar mais "o equilíbrio e a saúde em condições de trabalho determinadas" (HIRATA; KERGOAT, 2002, p. 266). Assim, no debate da psicopatologia ou psicodinâmica2 do trabalho, falar em sofrimento no trabalho não reside em apenas o "ponto de chegada ou o termo de um processo que une subjetividade ao trabalho", mas é, também, "um ponto de partida", no sentido de que

não é apenas uma consequência última da relação com o [trabalho] real, é ainda proteção da subjetividade rumo ao mundo em busca de meios para

\footnotetext{
2 Houve uma mudança da denominação, em 1992, de psicopatologia a psicodinâmica do trabalho, a qual, segundo Hirata (2004, p. 45), ocorreu no intuito de "indicar a ampliação do campo de análise à dinâmica, mais amplamente, das questões relativas à saúde mental, além das doenças do trabalho".
} 
agir sobre o mundo, para transformar este sofrimento encontrando os meios de superação da resistência do real. Assim, o sofrimento será ao mesmo tempo impressão subjetiva do mundo e origem do movimento de conquista do mundo. (DEJOURS, 2012, p. 26).

No aspecto de pensar as más condições ou o sofrimento no trabalho e as relações sociais de gênero, é Molinier (2013) que avança nas formulações sobre um processo de construção de estratégias coletivas de defesa ao sofrimento no trabalho pelas mulheres. Estas se sustentam em uma aproximação e compaixão entre mulheres com base no conceito de mulheridade (mulieritê), neologismo em referência oposta a "virilidade". Com base nessa compaixão pela condição comum é que as mulheres constituem coletivos no trabalho que têm o potencial da resistência.

Importante observar que o conceito de estratégias de defesa para as trabalhadoras foi desenvolvido por Molinier a partir das reflexões de Kergoat (2001, 2012), formuladora da sociologia das relações sociais de sexo ${ }^{3}$, sobre o silogismo das práticas das operárias, isto é, sobre a construção social dessas operárias como trabalhadoras que tinham uma representação de si dissociada do grupo social "mulheres operárias", já que viam as demais mulheres como invejosas ao mesmo tempo em que não se viam como invejosas - o que as leva a se verem, paradoxalmente, como "não mulheres".

Coadunando essa teoria à sociologia das relações sociais de sexo e procurando recuperar algumas contribuições mútuas que historicamente ocorreram - e que parecem ser pouco evidenciadas na atualidade - entre esses dois campos de estudos, procuro, então, trazer à tona esse instrumental de análise psicossociológico como heuristicamente útil para as análises sobre condições de trabalho, subjetividades e práticas de trabalhadoras.

\footnotetext{
${ }^{3}$ Relações sociais de sexo é um conceito desenvolvido por um grupo de intelectuais ligadas/os à Danièle Kergoat durante os anos 1980, na França (APRE, 1988). Sua elaboração tem propósitos e significados distintos do significado hegemônico do conceito de "gênero" que se internacionalizou a partir dos "gender studies", de origem anglófona. Embora as problemáticas levantadas pelas/os formuladoras/es da sociologia das relações sociais de sexo tenham referencial materialista e partam de questões atinentes às desigualdades entre os sexos no trabalho, nos movimentos sociais e das discussões entre relações de sexo e relações de classe (diferentemente do enfoque hegemônico dos estudos de gênero), não é incomum que se encontre, também, a utilização dos conceitos como intercambiáveis, a exemplo de "relações sociais de sexo/gênero". O que é possível afirmar é que "relações sociais de sexo" é um conceito menos conhecido que o de gênero no Brasil, então cabe esclarecer que "sexo" neste sentido diz respeito a uma construção social e afasta-se, portanto, de debates que naturalizem as desigualdades entre homens e mulheres, entre masculino e feminino.
} 


\section{As práticas sociais: um pilar da sociologia das relações sociais de sexo}

A reflexão que trago acerca do conceito "práticas sociais" deriva das reflexões da socióloga francesa Danièle Kergoat, uma das elaboradoras do conceito "divisão sexual do trabalho", entendido como desafio ou disputa central (enjeu) das relações sociais de sexo - concepção, que consiste em contribuição teórica relevante tanto para a sociologia do trabalho como para a teoria feminista.

O conceito divisão sexual do trabalho se desenvolve durante a década de 1970, na França, sob o impulso dos movimentos feministas, fundamentalmente a partir das reivindicações e denúncias em torno da massa de trabalho gratuito efetuado pelas mulheres no âmbito doméstico, não realizado para elas mesmas, mas para outro, sempre em nome de uma natureza ou dever femininos, cuja atribuição exclusiva às mulheres era tratada como natural, não era "visto" (invisível) e não reconhecido como deveria ser: como um trabalho (HIRATA; KERGOAT, 2008, p. 264).

A partir dessas lutas e reflexões surgem pesquisas sobre o trabalho doméstico e a reivindicação de seu reconhecimento como trabalho. Segundo Hirata e Kergoat (2008, p. 265), "isso permitiu considerar simultaneamente as atividades desenvolvidas na esfera doméstica e na esfera profissional, o que abriu caminho para se pensar em termos de divisão sexual do trabalho". Deste modo, o sentido inicial do conceito divisão sexual do trabalho correspondia a uma "articulação das duas esferas", a qual, contudo, teria logo se mostrado insuficiente e inspirou as pesquisadoras a passar a um segundo nível de análise: "a conceituação dessa relação social recorrente entre o grupo de homens e o das mulheres", de onde fezse surgir o conceito francófono "relações sociais de sexo" (HIRATA; KERGOAT, 2008, p. 265). Segundo as autoras, essa teorização é, na França, indissociável da ideia de divisão sexual do trabalho.

Desenvolve-se desde então uma sociologia das relações sociais de sexo, que parte de adotar o raciocínio analítico em termos de relações sociais (com seu corolário: as práticas sociais). Hirata (2002) esclarece que "relação" [rapport] significa:

Contradição, antagonismo, luta pelo poder, recusa de considerar que sistemas dominantes (capitalismo, sistema patriarcal) sejam totalmente determinantes. Em resumo, o que é importante na noção de relação social definida pelo antagonismo entre grupos sociais - é a dinâmica que ela introduz, uma vez que volta a colocar a contradição, o antagonismo entre os grupos sociais no centro da análise, e que se trata de uma contradição viva, perpetuamente em via de modificação, de recriação. (HIRATA, 2002, p. 244). 
Hirata e Kergoat (2008) afirmam que pensar o trabalho a partir tanto da articulação entre trabalho produtivo e reprodutivo como indissociado das relações sociais de sexo teve muitas consequências:

Depois que a "família", na forma de entidade natural, biológica, se esfacelou para surgir prioritariamente como lugar de exercício de um trabalho, foi a vez de implodir a esfera do trabalho assalariado, pensado até então apenas em torno do trabalho produtivo e da figura do trabalhador masculino, qualificado, branco. (HIRATA; KERGOAT, 2008, p. 265).

Hirata e Kergoat (2003, p. 114) aprofundam essa conceituação ao definirem a divisão sexual do trabalho não apenas como desafio das relações sociais de sexo, mas também como mediação entre relações sociais e práticas sociais:

As relações sociais (de sexo) estão encarnadas na materialidade social pelas modalidades, pelas formas, pela periodização das práticas sociais. A divisão sexual do trabalho é o suporte empírico que permite a mediação entre relações sociais (abstratas) e práticas sociais (concretas) e a elaboração de hipóteses de médio alcance.

Neste texto, a recuperação do conceito de práticas sociais se faz de modo a situála como um dos pilares das teorias de Kergoat e Hirata sobre relações sociais de sexo e da divisão sexual do trabalho.

Kergoat (2010) delimita que sua obra se propõe a compreender as práticas sociais tanto de homens como de mulheres "de maneira não mecânica" (...) "frente à divisão social do trabalho em sua tripla dimensão: de classe, de gênero e origem (Norte/Sul)". Para tal, mobiliza os conceitos de consubstancialidade e coextensividade das relações sociais, as quais não desenvolverei neste $\operatorname{artigo~}^{4}$. Esse posicionamento contra uma mecanicidade analítica das práticas de trabalhadores/as quer dizer se negar a explicar a razão de uma prática como derivação automática de um fator, mas sim "apreender práticas sociais em termos de relações sociais", assim como propõe uma análise que não enquadre os conflitos no trabalho como separados de forma excludente - ou de classe, ou de sexo, ou de raça.

A categoria "práticas sociais" pode ser encontrada nas análises empregadas por Danièle Kergoat buscando um enfoque que não se restrinja a examinar as formas

\footnotetext{
4 Segundo Kergoat (2010), "as relações sociais são consubstanciais; elas formam um nó que não pode ser desatado no nível das práticas sociais, mas apenas na perspectiva da análise sociológica". Para uma explanação sobre o conceito de consubstancialidade, ver Kergoat $(2010,2016)$.
} 
de subordinação dos trabalhadores e trabalhadoras, mas também os/as observar como sujeitos dotados de práticas. Tais práticas variam segundo o sexo de quem trabalha, o que faz erigir também a formulação do conceito de "sujeito sexuado" (KERGOAT, 2001 [1987]). A noção de sujeito sexuado é uma das dimensões da teoria da divisão sexual do trabalho e se situa, segundo Hirata (1995, p. 41) no contexto da "afirmação de um laço indissolúvel entre opressão sexual (e de classe) e exploração econômica (e de sexo)", compreendendo deste modo as relações sociais de sexo e de classe como coextensivas, das quais faz parte uma "subjetividade atuante, ao mesmo tempo 'sexuada' e 'de classe'".

Kergoat (2010) realiza uma distinção entre relação intersubjetiva e relação social: afirma ela que mesmo que algumas mudanças ocorram, por exemplo, na vida de alguns casais considerando uma divisão sexual do trabalho doméstico menos desigual (relações intersubjetivas), isso não impede que relações sociais (rapports sociaux) continuem a operar e a se manifestar sob suas três formas canônicas: exploração, dominação e opressão (KERGOAT, 2010, p. 95).

Dito isso, Kergoat (2010) precisa melhor o que compreende por práticas sociais ao destacar uma diferença de nível de alcance: "são as práticas sociais - e não as relações intersubjetivas - que podem dar origem a formas de resistência e que podem, portanto, ser as portadoras de um potencial de mudança no nível das relações sociais". (KERGOAT, 2010, p. 95). Em outras palavras, práticas sociais e não mudanças em contextos individuais, restritos ou específicos (relações intersubjetivas) são as que carregam a potência de transformação estrutural das relações de exploração, dominação, opressão.

Ao analisar as práticas sociais de operárias especializadas, Kergoat (2001, p. 107) afirma que não é possível reduzir as referências a elas segundo binômios trabalho/família, trabalho assalariado/trabalho doméstico ou ainda opressão/exploração, argumentando que "as práticas sociais femininas formam um conjunto complexo e ambivalente que varre constantemente, no tempo e no espaço, a totalidade do social".

Essa visão de ambivalência de práticas que se estendem à totalidade do social se sustenta em situações que a autora originalmente encontrou em pesquisas junto às operárias especializadas, a exemplo do fato de que elas "se agarram, e muito, à sua atividade e a seu emprego, bem como aos benefícios secundários que tanto um como outro lhes proporcionam em termos de socialização", além de chegarem a afirmar que em situações extremas da vida "o trabalho lhes salvou", ao mesmo tempo em que, por outro lado, não gostam de seu trabalho e permanecem com o sentimento de "estrangeirismo" com relação ao universo industrial (KERGOAT, 2001, p. 107-108). 
Considero relevante também examinar o exemplo utilizado por Kergoat para realizar essa distinção entre relações intersubjetivas e práticas sociais no contexto do que chama de um movimento social (que é também sindical) da "Coordenação Enfermeira":

O exemplo da Coordination Infirmière, movimento social do fim da década de 1980 na França, é esclarecedor. Nas reuniões do movimento, o convívio era inegavelmente feminino: as integrantes faziam questão de chamar-se pelo nome, perguntar sobre a saúde, comentar uma roupa nova ou uma ida ao cabeleireiro etc. São formas de relação intersubjetiva que suavizam o clima das reuniões, mas que não afetam de maneira alguma a dinâmica da dominação masculina no interior do movimento. Assim que uma disputa surgia no horizonte, os velhos mecanismos voltavam ao seu lugar (por exemplo: quem falará à imprensa?). (KERGOAT, 2010, p. 95).

A ênfase de Kergoat ao apontar que tais práticas entre trabalhadoras que suavizam o clima de reuniões e que possivelmente criam elos entre as mulheres não afetam, por si mesmas, a dinâmica de dominação masculina é crucial ao marcar posição sobre o desafio do enfrentamento dessas transformações mais profundas o que significa superar qualitativamente a dimensão intersubjetiva das relações.

O argumento de Kergoat se desenvolve agregando à categoria " práticas sociais" a noção de que sua efetividade transformadora depende de que se trate de práticas coletivas:

O que pode de fato questionar as relações sociais de sexo são as práticas sociais coletivas: por exemplo, decisões como quais as mulheres que terão as responsabilidades formais (presidência da associação) e práticas (responsabilidades organizacionais durante as manifestações), ou a decisão de que haja um aprendizado coletivo em situações de fala diante de um público etc. (KERGOAT, 2010, p. 95).

Trata-se, pois, de ações tomadas em conjunto que podem ser transformadoras também para o conjunto das mulheres. Destaco que essas transformações se referem a diversos aspectos da condição material dessas trabalhadoras, mas que todas envolvem, no caso da Coordenação Enfermeira analisada por Kergoat, a ocupação de espaços antes restritos às mulheres (direção de entidade, organização de manifestação, fala pública) e lhes permitem desenvolver um aprendizado coletivo.

Com práticas que proporcionam ocupar novas posições e aprendizados, não somente a condição de trabalho ou de luta, mas as próprias trabalhadoras como 
grupo social são distintas, porque "se transformaram em um sujeito coletivo produtor de sentido e sujeito de sua própria história". Deste modo,

Elas saíram da imagem imposta de feminilidade para se tornarem mulheres portadoras de poder de ação na construção e no desenvolvimento das relações sociais. Por meio delas, o grupo social "mulheres" apropriou-se de outras maneiras de pensar e agir, de outras formas de "produção social da existência humana". (KERGOAT, 2010, p. 95).

As pesquisas de Kergoat sobre trabalhadoras procuram demonstrar o modo original pelo qual se inscrevem nas relações sociais de sexo, assim como nas relações sociais de classe. A autora dedicou parte de sua obra a investigar e demonstrar essa originalidade de práticas sociais justamente a partir da análise de lutas dessas trabalhadoras, da sua constituição como sujeitos coletivos, sempre em transformação e irredutíveis a uma única categoria (KERGOAT, 2010, p. 96). Isso se desdobrou não somente em um legado de análises acumuladas, mas também em um método de análise:

Trata-se de um esforço para pensar - e para fornecer um método para pensar - tanto a pluralidade dos regimes de poder como a alquimia que transforma, em mais ou menos longo prazo, esta dominação interiorizada em práticas de resistência. É, portanto, um método para detectar os germes de utopia na realidade social contemporânea. (KERGOAT, 2010, p. 103).

Tal método se pauta, entre outros elementos, na compreensão dos grupos de trabalhadores/as não como estanques e meros alvos de ataques (exploração, opressão), mas como seres dotados de práticas "frequentemente ambíguas e ambivalentes", ou, em outras palavras, trata-se de um método que "permite recolocar no centro da análise o sujeito político (e não a vítima de múltiplas dominações)". (KERGOAT, 2010, p. 103).

Esse conceito e esse método de análise carregam em si uma visão que não encerra a realidade em um "beco sem saída" de reprodução das relações sociais, mas que vislumbra a possibilidade de sua superação. Segundo Kergoat, "devemos estar atentos à maneira como os dominados reinterpretam e subvertem as categorias: isso impede sua reificação. Porém, a subversão só pesa sobre as relações sociais se for coletiva". (KERGOAT, 2010, p. 100). 


\section{As estratégias coletivas de defesa}

Quando se pensa em relações de resistência no trabalho sob a ótica da sociologia do trabalho, a imagem possivelmente mais explícita seja a de greves, manifestações ou algum tipo de prática correlata. Porém, há outras formas cotidianas de resistência aos constrangimentos no local de trabalho que expressam, também, formas de defesa dos trabalhadores ao modo pelo qual o trabalho assalariado lhes é impelido, isto é, as defesas aos constrangimentos do trabalho.

Uma das contribuições mais relevantes neste sentido é a trazida pelo corpus teórico psicodinâmica do trabalho, do qual, segundo Molinier (2013), a descoberta mais original e mais importante foi "a existência de estratégias coletivas de defesa". Tais estratégias consistem em mecanismos construídos pelos trabalhadores para "produzir um domínio sobretudo simbólico dos riscos aos quais o trabalhador se impõe", não em sentido estrito de barrar os riscos, mas à forma como são sentidos, uma vez que tais estratégias "não modificam o risco objetivo, apenas sua percepção". (MOLINIER, 2013, p. 217).

Essas estratégias se demonstram a partir da produção de uma cooperação defensiva por meio da qual

é possível garantir as condições sociais de uma transformação da subjetividade que permite, pode-se dizer assim, 'anestesiar' o sofrimento, ao conjugar o esforço de todos para não ficar prisioneiro justamente das dimensões da atividade que causam sofrimento, e evitá-las ao máximo de suas possibilidades. (MOLINIER, 2013, p. 217).

A autora salienta, contudo, que as estratégias coletivas de defesa "são necessárias para a saúde mental, mas apresentam o inconveniente de produzir distorções da comunicação ao impedir de pensar naquilo que provoca sofrimento e que seria importante transformar" (MOLINIER, 2013, p. 218).

Trata-se, ao menos em um primeiro momento, de examinar as maneiras de lidar com o sofrimento para que se possa conseguir continuar trabalhando e por vezes encontrar prazer na realização do próprio trabalho, mesmo que não se inobserve que é a partir do trabalho que existe a possibilidade de avançar em compromissos favoráveis não somente à conquista da saúde, mas para a busca da emancipação. Afirma Dejours que "mesmo submissa a uma dupla dominação - a dominação social e a dominação de gênero - foi por causa do trabalho que as mulheres progrediram em seus movimentos de emancipação". (DEJOURS, 2012, p. 14).

A psicodinâmica do trabalho analisou, pois, determinadas práticas que antes eram consideradas como "condutas insólitas" da parte de trabalhadores como 
maneiras encontradas por estes para lidar psicologicamente com trabalhos perigosos e de maneira geral com os medos que provocam certos trabalhos (medo de acidente, de machucar-se, da paralisia, da morte, medo de contaminação, do erro profissional, de não dominar sistemas técnicos, de ser substituído, de não estar à altura do cargo, entre outros), com vistas a sua própria preservação (MOLINIER, 2013, p. 220-221).

O setor de construção civil é um entre os utilizados como exemplo para ilustrar o tipo de "condutas insólitas" que a psicodinâmica do trabalho reinterpreta como uma estratégia coletiva de defesa. Com base na ideia de que para trabalhar o medo deve ser superado, os trabalhadores desenvolvem "comportamentos arriscados, competições perigosas (...), negações incompreensíveis a respeito de determinações de segurança, piadas, anedotas que debocham daqueles que deixam escapar sinais de fraqueza" (MOLINIER, 2013, p. 223). Um exemplo é o de trabalhadores que içam um colega que está com os equipamentos de proteção pelo guindaste e o conduzem por todo o canteiro.

Tal tipo de atitude perigosa teria um sentido de impedir a manifestação do medo antes que ele apareça, agindo para tentar reverter a posição de "vítimas passivas" a "agentes ativos de um desafio, de uma atitude provocadora ou de uma zombaria em relação aos constrangimentos do trabalho" (MOLINIER, 2013, p. 223).

Entre tais mecanismos há fatores em comum, como o de mobilizar e exercitar as habilidades e a destreza profissional por meio de "proezas" e de reafirmar valores de coragem e de virilidade. Esse tipo de comportamentos pode chegar ao ponto de, em nome de um exibicionismo da virilidade ou de um "heroísmo", trabalhadores minimizarem a gravidade de acidentes dos quais são e foram vítimas. Isso seria uma maneira de criar a ilusão coletiva de domínio da situação e, ao mesmo tempo, uma negação coletiva do risco. Tal negação, para ser eficiente, deve ser construída e mantida de forma coletiva (MOLINIER, 2013, p. 224).

Há desdobramentos menos explícitos, mas de extrema relevância, desse tipo de conduta: não se trata apenas de um meio de tentar retomar as rédeas de um suposto controle; a heroicização e estetização da coragem dos trabalhadores "podem facilmente converter-se no eufemismo de sua exploração, ou pura e simplesmente na dissimulação desta". (MOLINIER, 2013, p. 226).

Molinier defende também a hipótese de que as práticas que convocam a exaltação da virilidade associadas à sexualidade teriam essa intenção defensiva. Segundo ela, "a luta contra o sofrimento no trabalho mobiliza certos atos ou representações relevando de um tratamento pornográfico da sexualidade tal como um sem número de apetrechos a serviço da virilidade defensiva" (MOLINIER, 2013, p. 231), o que daria sentido a certas "brincadeiras" de conotação sexual no 
espaço de trabalho. Isto porque, por meio delas, "a sexualidade é tratada em um registro defensivo que edifica uma barreira à emoção, à desordem erótica, à sensibilidade, ao desmoronamento de si, à passividade e ao encontro autenticamente desestabilizador com o outro". (MOLINIER, 2013, p. 231).

Vale destacar que, no sistema de valores viril, o feminino simboliza "a vulnerabilidade psíquica e a fraqueza moral" (MOLINIER, 2013, p. 232), o que poderia explicar por que as mulheres acabam sendo alvo mais comum dessas condutas defensivas viris. Segundo as estereotipias viris, as mulheres autorizadas a participar da sociabilidade masculina são, segundo Molinier, as "safadas" ou que dão alguma prova simbólica de sua fidelidade, sem mencionar as que buscam escapar de represálias viris "escondendo suas ambições atrás da máscara de uma feminilidade exacerbada" ou ainda as que dizem "fazer cara de paisagem durante o tempo todo para passarem desapercebidas" (MOLINIER, 2013, p. 233).

O que é possível apreender com o argumento de Molinier é que o cotidiano de mulheres, quando minoritárias no local de trabalho, é de uma luta contínua por simplesmente conseguir trabalhar. Assim, "para as mulheres, adaptar-se aos ofícios masculinos é sempre fonte de um conflito identitário, visto as representações todas centradas na virilidade, quando a mulher passa a ser julgada como feminina ou 'respeitável'". (MOLINIER, 2013, p. 232).

A possibilidade de superação do conflito para as mulheres se adaptarem nesses espaços existe, por meio de "estratégias individuais de virilidade, de ironia, de desfaçatez ou de discrição", mas não subestima que as mulheres, notadamente as altamente qualificadas, acabam recorrendo a outro tipo de estratégia, que reside nas reconversões profissionais - isto é, sair daquele local de trabalho, mudar de setor ou mesmo de emprego. Nestes casos, o que acaba se efetivando são "estratégias de sobrevida psíquica para driblar as ofensas da virilidade". (MOLINIER, 2013, p. 233).

Seu argumento faz refletir sobre como um ambiente de trabalho no qual as mulheres são minoritárias dificulta a elas possibilidade de estratégias coletivas de defesa, uma vez que ter que lidar com a minimização do próprio sofrimento em um ambiente de trabalho hostil, com práticas viris dos colegas, apresenta possibilidades restritas às mulheres: ou "adaptam-se" a esse ambiente viril ("aceitando" ou mesmo reproduzindo comportamentos viris) caso queiram ou precisem nele permanecer, ou dele são conduzidas a se retirar - ambas atitudes em nome da sobrevida psíquica. 


\section{0 encontro entre a psicodinâmica do trabalho e a sociologia das relações sociais de sexo}

Conforme recupera Molinier (2013, p. 253), a relação entre saúde e trabalho foi, durante os anos 1980, "conceitualizada principalmente por homens, a partir de pesquisas clínicas realizadas em sua maioria junto a trabalhadores do sexo masculino no exercício de profissões envolvendo algum perigo". Foi em 1988, em um seminário interdisciplinar sobre "Prazer e Sofrimento no Trabalho", que as sociólogas Danièle Kergoat e Helena Hirata causaram grande alvoroço ao colocarem a questão de saber "se a psicodinâmica do trabalho poderia se eximir das relações sociais de sexo". (MOLINIER, 2013, p. 254).

As contribuições dessas duas autoras a respeito da transversalidade das relações sociais de sexo a todo campo social, e, portanto, a todos os campos disciplinares, e que tal problemática dizia respeito aos homens e às mulheres, ao trabalho assalariado e ao doméstico, estão, segundo Molinier (2013, p. 254), na “origem de remanejamentos teóricos, em seguida metodológicos, de envergadura, que ocorreram e continuam acontecendo, com impactos decisivos sobre o conjunto do programa científico da psicodinâmica do trabalho".

Em outras palavras, são as contribuições dessas duas sociólogas formuladoras da categoria analítica já consagrada "divisão sexual do trabalho" as responsáveis por provocar também uma reflexão que levasse em conta as relações sociais de sexo nas formulações da psicodinâmica de trabalho. Essa clivagem é de extrema relevância, uma vez que, pontua Molinier (2013, p. 257), "as relações sociais de sexo representavam o ponto cego da psicodinâmica do trabalho".

Até então as escolhas distintas de profissão feitas por homens e mulheres eram explicadas com base em orientações psicológicas diferenciadas, fazendo com que as tarefas estivessem em ressonância simbólica com tais orientações psicológicas (feminina ou masculina) - uma concepção, portanto, naturalista e harmônica da divisão sexual do trabalho. E o que explicaria escolhas atípicas à orientação psicológica de cada sexo seria uma "bissexualidade psíquica", isto é, a visão de que em cada um há "uma parte feminina e outra masculina, com uma dosagem diferente em cada caso" (MOLINIER, 2013, p. 255) - uma visão menos rígida de adequação de certas profissões a determinados sexos, mas de todo modo igualmente essencialista com relação a haver uma orientação psicológica "feminina" ou "masculina". Toda essa construção foi questionada pelos/as sociólogos/as do trabalho com base nas elaborações acerca das relações de classe e de sexo.

Kergoat e Hirata (2002 [1988], p. 269-271) apontaram explicitamente, no 
trabalho apresentado no referido congresso em 1988, quais seriam tais pontos cegos à psicodinâmica do trabalho:

i. A identificação de que até então nem a análise do trabalho monótono e repetitivo nem a análise dos coletivos de trabalho levavam em conta a constatação fundamental do sexo de quem realiza as atividades - sobretudo mulheres em atividades industriais monótonas e repetitivas e homens em indústrias de processo contínuo, na construção civil. Sendo de acordo com o sexo que as empresas elaboram sua política de gestão e controle sobre o trabalho, diferenciada para homens e mulheres, as autoras se questionam "como se pode falar do sofrimento e do prazer no trabalho sem antes se considerar todo o tipo de controle ao qual os trabalhadores e as trabalhadoras estão submetidos?".

ii. A não consideração das implicações psicopatológicas da representação social da virilidade e da feminilidade ${ }^{5}$, elementos que podem, segundo as autoras, ter relação direta com a vivência do prazer no trabalho, bem como estar na base das ideologias defensivas de uma profissão. Vale destacar como as autoras examinam a construção social do medo segundo os sexos: "não ter medo não tem o mesmo significado para um homem educado desde a infância na ética da coragem e para uma mulher que deverá ser fraca e dependente". A consequência dessa diferença é a de que o imperativo da ausência de medo (referida por conta das estratégias dos homens para encarar trabalhos perigosos, arriscando-se de forma a antecipar-se ao medo) não pode ser mobilizado da mesma maneira para o trabalho e para a criação de coletivos de defesa, porque varia segundo os sexos.

iii. A não articulação, na análise da psicopatologia, entre estruturas familiares e sistema produtivo, trabalho doméstico e trabalho profissional, porque concentrada no local de trabalho e exercício da atividade profissional. Essa conduta faria escaparem à análise as distinções tanto na vivência do trabalho como na do desemprego segundo a condição de ser casado/a ou solteiro/a, morar sozinho/a ou com os pais, as implicações distintas quanto à maternidade ou à paternidade. Por exemplo, estar desempregado e ser a pessoa com principal responsabilidade financeira na família pode implicar a maior aceitabilidade de condições de trabalho mais penosas e precárias. E

\footnotetext{
${ }^{5}$ As autoras reconhecem que na psicopatologia existia o uso de conceitos como "viril" e "virilidade" para designar os comportamentos de operários, mas apontam a ausência de "uma conceitualização em termos de masculinidade e de feminilidade sociais". (HIRATA; KERGOAT, 2002 [1988], p. 270)
} 
estar desempregado pode ter implicações distintas sobre a identidade social segundo os sexos, uma vez que pode afetar psicologicamente valores como a virilidade nos homens, mais associada à condição profissional, do que a feminilidade nas mulheres, menos associada a "ter um emprego".

A problemática do prazer e do sofrimento no trabalho foi construída desde então procurando dar conta da "materialidade dos constrangimentos do trabalho" que "não se situavam na continuidade da história pessoal, mas impunham independente da vontade do sujeito", o que quer dizer que "a experiência do trabalho não repetia a história infantil" (MOLINIER, 2013, p. 257). Assim, tratavase tanto de municiar-se de uma teoria social que se ligasse à psicologia individual, como também de escapar das análises que tratassem do sujeito como reduzido a um "reflexo do social", como se fossem marionetes sem consistência psíquica uma análise que impediria pensar o processo de emancipação.

A sociologia das relações sociais de sexo propicia justamente um estatuto privilegiado ao antagonismo, ao conflito e à ideia de movimento social sexuado. Kergoat (2001) traz como contribuição essa análise das relações sociais como dinâmicas e que, portanto, permitem pensar e trabalhar a liberdade.

Isso faz com que seja possível compreender pontos de conexão e de contribuição mútua entre esses dois campos da teoria social: tanto a psicodinâmica como a sociologia das relações sociais de sexo têm no trabalho uma questão central. A partir desse eixo alguns elementos puderam ser trazidos inclusive à teoria das relações sociais de sexo, a exemplo da agregação por Kergoat e Hirata de questões como a da pertinência em pensar, no debate sociológico, em trabalho e subjetividade de forma conjunta, além de provocar formulações sobre o vínculo entre emancipação e saúde mental (MOLINIER, 2013, p. 258).

Ao examinar convergências entre a conduta psicopatológica e a da divisão sexual do trabalho, afirma Hirata (HIRATA; KERGOAT, 2002, p. 265) que ambas têm em comum oferecer explicações que agregam elementos que operam sob a lógica de contradições que não se restringem à da exploração (caráter social do trabalho e apropriação privada do lucro): de um lado, a psicopatologia mostra a importância da contradição "entre o caráter social do trabalho e o caráter singular da doença mental, introduzindo assim a noção de uma subjetividade ativa, envolvida no processo de trabalho". De outro, a sociologia das relações de sexo desvenda relações de opressão e de dominação de homens e mulheres no universo do trabalho assalariado e na família, indicando outras contradições além da criada pela relação de exploração. Ambas condutas, contudo, não estão apartadas do debate acerca da exploração, mas sim fornecem contribuições sobre relações 
essenciais para a reprodução do circuito da troca mercantil.

Além disso, Hirata (HIRATA; KERGOAT, 2002, p. 266-267) analisa haver uma impressionante semelhança entre ambas teorias em termos de tentar "fazer reconhecer o que antes era só considerado como negativo" e "tornar visível o que era invisível", o que ela exemplifica por meio

i. do combate pela sociologia das relações sociais de sexo à ideia de que mulheres fora do trabalho assalariado "não trabalham", demonstrando que o trabalho doméstico exige tempo, gasto de energia e esforço físico consideráveis, além de sustentar que "é apenas na responsabilidade simultânea, doméstica e assalariada, do trabalho, que se pode ver nascer o valor";

ii. da conduta da psicodinâmica do trabalho de reelaborar a ideia de que o trabalho feito por operários especializados seria fácil e desqualificado, apontando que em realidade demanda uma considerável energia, sobretudo se considerado o esforço psíquico necessário para se submeter à organização científica do trabalho quando se trata de trabalhos repetitivos, monótonos, fragmentados.

iii. da conduta na sociologia, similar à anterior, de analisar as origens da desqualificação feminina, que também reelabora esta atribuição "trabalho desqualificado" sobre operárias desqualificadas para afirmar que em realidade há uma desvalorização e não reconhecimento da qualificação que essas trabalhadoras adquiriram fora dos canais de formação profissional correntes, isto é, inverte-se a proposição para afirmar que elas são sim bastante qualificadas para o tipo de trabalho que lhes é designado.

Seguimos Hirata (2004) quando afirma que a questão "A psicopatologia do trabalho, em sua abordagem do sofrimento e do prazer no trabalho, pode deixar de lado as relações sociais de sexo?" levantada por ela e Kergoat continua atual e avalia ter havido de fato contribuições mútuas e diálogos entre esses campos teóricos desde os anos 1980.

De acordo com Hirata (2004, p. 47), a dimensão das relações sociais homensmulheres, da virilidade e da mulheridade como construções sociais, foi integrada de maneira bastante central tanto na produção científica quanto nas atividades (notadamente os três colóquios internacionais de psicodinâmica e de psicopatologia do trabalho) do laboratório de pesquisa criado por Dejours na França nos anos 1990. Do mesmo modo, a questão inversa, "pode-se deixar de lado a psicodinâmica do trabalho em uma abordagem em termos da divisão sexual do 
trabalho? também seria ainda válida, e sua resposta estaria na própria incorporação de Danièle Kergoat da problemática da subjetividade do trabalho: "a atividade de trabalho é produção de si" (...), não se pode "pensar o trabalho, compreendido sociologicamente, sem levar em conta a subjetividade" (KERGOAT, 2001).

Tais contribuições mútuas podem ser evocadas, segundo Hirata (2004, p. 47), em duas problemáticas de pesquisa: uma delas é a da continuidade das relações sociais de sexo no trabalho e fora dele, desenvolvida originalmente pela sociologia das relações sociais de sexo, mas que recebe importantes contribuições da psicodinâmica, por exemplo, quando associada ao desenvolvimento de identidades sexuadas no trabalho. Essa visão de ambos campos teóricos sobre a integração trabalho/extratrabalho também permite esclarecer a reprodução da hierarquia entre os sexos com supremacia masculina. A outra problemática é a da centralidade do trabalho, que admite, em ambas as teorias, uma concepção ampla de trabalho (que leva em conta o trabalho assalariado e o doméstico como espaços conexos) a partir da qual se pode falar, segundo Hirata, tanto da apreensão da dimensão do trabalho no funcionamento psíquico como das funções psíquicas que operam na divisão sexual do trabalho.

\section{Estratégias de defesa dos trabalhadores = às das trabalhadoras?}

As teorias desenvolvidas originalmente na psicodinâmica do trabalho foram examinadas sob uma leitura sexuada por Kergoat e Hirata (2002 [1998]), que mostraram que essas estratégias coletivas de defesa erigidas em meios de trabalho masculinos eram expressão de uma virilidade social - isto é uma virilidade socialmente construída. Esta, por sua vez, seria uma das fontes ao mesmo tempo de prazer no trabalho (coibindo a expressão do medo e do sofrimento) para esses homens como também um meio de "compensar" narcisicamente as relações de exploração.

Esse tipo de atividade que convoca a virilidade estaria do lado contrário das atividades suscetíveis de fragilizar a posição viril, porque diz respeito à vulnerabilidade humana, às quais são atribuídas às mulheres (MOLINIER, 2013, p. 260-261).

Deste modo, restava a indagação sobre a existência ou não de estratégias coletivas de defesa femininas, que não necessariamente expressassem esta virilidade social. Nas pesquisas sociológicas de Kergoat, a autora pôde encontrar situações que permitiram afirmar que o coletivo de operárias existia, sim, mas apenas em período de luta e que, no cotidiano, o grupo operário feminino aparecia atomizado e, segundo a representação que lhes davam as operárias, caracterizado 
por uma intensa concorrência interindividual. Assim definem algumas particularidades do coletivo de trabalho das mulheres:

(...) um coletivo operário feminino de lutas obedece a uma lógica (...) [na qual] o igualitarismo não é mais colocado a priori: o que é proposto como objetivo a ser atingido pelo grupo é a igualdade de participação na luta. Enquanto os homens, em uma luta, teriam a tendência de negar as diferenças, as mulheres, ao contrário, as colocam como problema para resolver: existem as casadas, cujos maridos não querem que participem da ocupação no local de trabalho, enquanto as solteiras podem participar da ocupação à noite. Existem as que têm filhos e as que não têm. O que fazer? E há o estabelecimento de uma estratégia, ou, sobretudo, de uma prática social que tende ao igualitarismo, ou seja, que tende a que todo mundo possa participar da greve da mesma maneira e, principalmente, a que todo mundo possa continuar a controlar o que se passa no nível da greve. (HIRATA; KERGOAT, 2002 [1988], p. 261).

De outra parte, entre as situações recorrentes encontradas por Kergoat (2001[1987]), no cotidiano do grupo operário feminino estava o problema da "inveja", assim como da "fofocaiada" e da boataria como características que trabalhadoras identificavam como sendo das demais e não de si mesmas.

Ao invés de enquadrar tais afirmações simplesmente como estereótipos sexuados, Kergoat (2001) lhes dá no plano da análise "a mesma importância que as operárias lhe outorgam", formulando a partir dessa constatação a elaboração de um silogismo segundo o qual as mulheres colocam tais elementos (inveja, ter medo do chefe, ser fofoqueiras) como atributos das outras; ao mesmo tempo, dissociamse dessas mesmas características, em um sentido que põe em evidência "a recusa de a operária indivíduo identificar-se a um grupo de pertencimento 'mulher' julgado de forma pejorativa segundo os estereótipos da ideologia dominante". Por conseguinte, o silogismo leva ao indizível sobre elas mesmas: que "não são mulheres". Assim, a constituição de um sujeito sexuado encontra-se bloqueada em sua esfera de representações (KERGOAT, 2001, p. 109).

Kergoat (HIRATA; KERGOAT, 2002 [1988]) avaliou que residia aí uma negação do grupo, que significa que as mulheres se neguem como sujeitos. A autora sustenta que, como os operários especializados, as operárias desvalorizam seus conhecimentos, suas experiências e, por consequência, se autodesvalorizam, mas que - e isso é fundamental - isso se soma a uma autodesvalorização como sexo, como se somente ao se diferenciar das demais mulheres elas conseguissem confirmar sua identidade individual (HIRATA; KERGOAT, 2002, p. 261). Por essa razão, Kergoat analisa: 
A autodesvalorização enquanto sexo é mais complexa do que a autodesvalorização enquanto operários ou operárias, porque, de certa maneira, isso equivale a negar a si mesmo (...): a personalidade é quebrada, fragmentada, e a dor assim produzida só pode ter consequências sobre a saúde mental. (HIRATA; KERGOAT, 2002, p. 262).

Essa forma de representação autodesvalorizada ou que se dá pela negação é exatamente o inverso do que ocorre entre os homens, entre os quais a identidade sexuada no trabalho vem por meio de assertivas, por exemplo: "ser homem é ser franco, corajoso, solidário, etc.". Porém, salienta Molinier (2013, p. 265), "a dificuldade extrema em produzir um nós sexuado feminino não significa a aceitação das relações de dominação, mas a incorporação da relação social de sexo, incorporação que participa da reprodução do sistema social de sexo". O que é evocado pelas mulheres operárias especializadas estudadas por Kergoat, o estereótipo do ciúme, é pejorativo, diferente dos "valores viris" mobilizados pelos homens, o que faz Molinier questionar sobre em que base ideológica se desenvolveriam estratégias coletivas de mulheres em outros locais de trabalho.

Como anteriormente colocado, se tomada como base a formação de coletivos de defesa ao sofrimento no trabalho com base em valores como virilidade e coragem - formulação que se derivou da análise de grupos profissionais eminentemente masculinos - para analisar espaços de trabalho nos quais a maioria são mulheres, o resultado provável seria, portanto, o de que entre mulheres tais coletivos de defesa simplesmente não existem.

Porém, ao invés de reproduzir a ideia de que a ciência produzida com base nos homens pode ser tomada como "neutro" e, consequentemente, como base para as análises sobre trabalhadoras ou trabalhadores indiferentemente, a contribuição da sociologia das relações sociais de sexo vem dizer justamente que existem sofrimentos no trabalho que são "femininos" ou "masculinos", porque derivados de sociabilidades e situações de trabalho distintas.

Molinier recupera que Dejours havia chegado a identificar, no lado oposto da virilidade, o neologismo "mulheridade" (mulierité) para designar a posição feminina cerceada ou mesmo alienada na submissão. Um exemplo é dado ao examinar o ingresso de mulheres que acessam profissões tradicionalmente masculinas: uma das mulheres, uma jovem paciente acompanhada por Dejours,

ao se recusar a repetição de um destino materno frustrado ("mulheridade"), deseja alcançar um trabalho interessante na área da eletrotécnica. Mas em seu meio social não há mulheres suscetíveis de representar um modelo de 
emancipação profissional e sexual. E no seu ambiente de trabalho, exclusivamente masculino, ela deve consentir em dobrar-se às estratégias coletivas de defesa e aos trotes concebidos por homens, com o risco de uma virilização. (...) decorre uma crise de identidade sexual (...) e uma dúvida sobre a orientação sexual (homo ou heterossexual) (MOLINIER, 2013, p. 262).

Molinier aponta que, nesse caso, Dejours supera o que seria a avaliação da psicanálise clássica de que "a luta trágica da jovem contra a 'mulheridade' seria (...) uma reivindicação fálica e uma recusa típica da castração" (DEJOURS apud MOLINIER, 2013, p. 263), para assumir que a paciente em questão não se reduz a um "homem castrado", mas se trata de "uma jovem mulher em busca do futuro" (MOLINIER, 2013, p. 263). Essa transição da forma de análise da conduta da trabalhadora, após o contato e incorporação de Dejours das reflexões provocadas pelo debate com Kergoat e Hirata, demonstra evidente salto qualitativo na análise, ao reconhecer que o fato de uma mulher desejar construir-se em uma profissão de maioria masculina, negando seu suposto "destino de gênero" da maternidade, não a caracteriza como portadora de nenhum lapso ou com reivindicações fálicas. Trata-se, pelo contrário, de uma aspiração perfeitamente compreensível como a aspiração de uma mulher.

Mas Molinier avança na concepção de "mulheridade" ao apontar que se trata justamente da "identidade defensiva do sexo" que

designa o conjunto das condutas pelas quais uma mulher se esforça para evitar as represálias das quais tem medo de ser vítima, se ela não se conformar ao que é esperado das mulheres. As condutas e atitudes esperadas por parte das mulheres são editadas, geralmente, e de maneira decisiva, pelo mundo dos homens, em função de seus próprios interesses, mas a conformização do sujeito-mulher às posturas da mulheridade operase também pela mediação do coletivo de trabalho feminino. (MOLINIER, 2004, p. 237).

Deste modo, sustenta Molinier (2004, p. 237), a "mulheridade" permite analisar, em termos de defesas contra o sofrimento no trabalho, um conjunto aparentemente não conexo de condutas femininas que conduzem a um tipo de alienação. Tal concepção de mulheridade como ideologia defensiva de sexo significa uma contribuição importante do campo da psicodinâmica do trabalho à questão da subjetividade e das práticas das mulheres no trabalho em termos de entender o caráter socialmente constituído, e não natural, dessas condutas. Tal linha de análise e de argumento abre, inclusive, caminhos para a quebra de preconceitos de certas 
áreas das ciências sociais sobre se tratar de "psicologismo" (MOLINIER, 2004, p. 41) abordar a problemática do sujeito e da subjetividade.

A resposta à questão sobre a existência de estratégias de defesa femininas no trabalho (e a relação entre estas e a constituição de coletivos de trabalhadoras), provocada por Kergoat e Hirata e continuada por Molinier, demandou a investigação de situações de trabalho feminino que possibilitassem a comparação com as já analisadas no trabalho masculino. Uma das profissões estudadas foi a da enfermagem, um trabalho "realizado sob a pressão permanente do medo (contaminação, erro, violência)", isto é, com similaridades ao trabalho masculino, mas com especificidades por ser orientado para a atenção dos outros e o alívio do sofrimento psíquico, o que o faz ser fortemente indexado ao feminino, no sentido social do termo (MOLINIER, 2013, p. 267).

Nesse setor profissional é identificada tanto a naturalização das competências femininas, sob análise sociológica, como a origem de um sofrimento específico pelo fato de o trabalho demandar a confrontação com o sofrimento de outra pessoa, a compaixão (sofrer com), sob o enfoque psicodinâmico. Assim, combinando esses dois enfoques, enfrentava-se o "natural" que ocultava o trabalho, mostrando que entre as enfermeiras

o que aparecia como expressão da personalidade dos indivíduos (sua gentileza, o humor sempre constante, sua compaixão) não estava presente nas alunas no início da profissionalização. Sua experiência se instaura antes sob o primado do medo e do nojo acompanhado de condutas de evitação (MOLINIER, 2013,0 p. 269).

Mais especificamente, evidenciava-se que a compaixão era um recurso não somente adquirido, mas que podia continuar sendo sustentado em decorrência dos constrangimentos organizacionais, caso se instaurasse uma verdadeira cooperação, como analisa Molinier (2013, p. 269): “A compaixão é um processo psíquico desencadeado pela obrigação de se confrontar com os doentes mesmo quando não se deseja. A compaixão não é primeira, ela advém em um segundo momento da experiência do trabalho".

Ao desenvolver ideia da compaixão como um sentimento e um comportamento aprendido socialmente, Molinier afasta-se de qualquer essencialização da compaixão como um atributo exclusivo da feminilidade. A autora chega, inclusive, a propor que o aprendizado da mesma carece ser desenvolvido entre os homens, enquanto entre as mulheres, talvez até excessivamente já socializadas para a compaixão, careceria ser desenvolvido o egoísmo - sendo ambos, compaixão e egoísmo, necessários a todos e todas (MOLINIER, 2006, p. 14). 
Sob a análise a partir da teoria da psicodinâmica do trabalho, observa-se que a manutenção da atitude de compaixão em relação a pacientes considerados repugnantes se sustenta muitas vezes em margens de manobra das equipes para se organizarem de forma a "enfrentar conjuntamente a repulsa" ${ }^{6}$. Assim, colegas presentes que não estão diretamente atuando com o paciente têm também um trabalho de distraí-lo ao mesmo tempo em que "asseguram apoio psicológico à colega que está dispensando diretamente os cuidados necessários ao paciente, brincando com ela, falando de tudo e de nada, estando simplesmente ali marcando presença" (MOLINIER, 2013, p. 269).

Diferentes ou mesmo opostas às estratégias viris, as estratégias coletivas de defesa das enfermeiras aparecem como cooperação defensiva nos matizes específicos de sua convivialidade, a qual desejam afastar de estereótipos sexuados, por exemplo, "papo de comadres". Elas realizam trocas entre si sobretudo nas pausas do trabalho, nas quais discutem de modo a "elaborar o sofrimento gerado pelo trabalho hospitalar sem opor-lhe uma sistemática rejeição" (MOLINIER, 2013, p. 271).

Em tais espaços as mulheres intercambiam desde informações importantes para o desenrolar das atividades até a expressão de seus pontos de vista, sentimentos, dúvidas, inquietações, impotência, afinidades e nojo, partilhando situações patéticas ou proezas de inventividade e fantasia para desdramatizar situações vividas e tornar o dia mais divertido. Esses espaços têm, segundo Molinier (2013, p. 273), um sentido de elaboração coletiva para as trabalhadoras de "recursos simbólicos que permitem tornar o mundo um mundo no qual se pode viver sem esvaziá-lo, no entanto, do sofrimento" ${ }^{7 "}$.

Molinier revela que esses espaços coletivos de troca são permeados por zombaria - dos pacientes, dos membros da diretoria da enfermagem, dos médicos, mas, sobretudo, delas mesmas, o que a leva a afirmar que

a dimensão do autoescárnio em relação à própria vulnerabilidade é o componente essencial das defesas "femininas". A confissão da vulnerabilidade é congruente com a feminilidade. No inverso, gracejar sobre suas fraquezas, suas dificuldades, as derrotas, é inconcebível na perspectiva viril

\footnotetext{
6 Associo este exemplo ao dado por Dejours (1993, p. 297-298) sobre os trabalhadores que solidariamente se expunham em conjunto à radiação partilhando o tempo de tarefa na qual isso era proibido (a prescrição do trabalho dizia para que realizassem a tarefa em turnos). O pesquisador descobriu que os trabalhadores, devido à mobilização de sua inteligência criativa, descobriram que estariam sempre a "receber doses" de radioatividade não importa a precaução que tivessem, por isso decidiram à revelia das chefias realizar esta modificação nos processos de trabalho.
}

${ }^{7}$ Grifo da autora. 
(MOLINIER, 2013, p. 273).

A assertiva de que a confissão da vulnerabilidade se converte no ponto essencial das defesas das mulheres é um ponto alto do argumento de Molinier, que a conduz a sustentar que "há realmente uma sexualização das defesas", não em um sentido de atributo natural, mas sim, como no exemplo das enfermeiras, pela capacidade desenvolvida, por meio de seu trabalho de amparo, de "reconhecer em si suas próprias fraquezas e tolerá-las nos demais" (MOLINIER, 2013, p. 273).

Molinier arremata o argumento convocando a um olhar sobre a pertinência em um sentido de renovação das reflexões sobre o trabalho, de considerar as bases materiais dessa experiência concreta das mulheres:

Se for para renovar a reflexão moral apoiando-se na experiência concreta das mulheres, é necessário considerar a base material desta experiência, ou seja, a divisão sexual do trabalho, a divisão do "trabalho sujo", as relações de classe, de raça ou de etnia e de sexo, tal como as estratégias coletivas de defesa (MOLINIER, 2013, p. 275).

Também em um sentido de renovação de reflexões sobre o trabalho, Kergoat e Galerand (2008) analisam que o fato de as mulheres chegarem a construir uma relação positiva com o trabalho, ainda que este seja fortemente desvalorizado, seja significativo de um potencial subversivo. Tal potencial é demonstrável por meio do sentimento de serem úteis e produtivas que as trabalhadoras não qualificadas chegam a construir e a opor à desvalorização quantitativa e qualitativa de seu trabalho (KERGOAT; GALERAND, 2008, p. 71).

Rumar desse potencial subversivo a um caminho concreto de emancipação consiste, para as autoras, em encontrar formas de luta coletiva que contestem a desqualificação do trabalho feminino simultaneamente pelas frentes do trabalho assalariado e do trabalho doméstico. Tal caráter emancipador demandaria organização coletiva que permita transformar resistências individuais em práticas coletivas e reivindicativas. Esse é o questionamento que Kergoat e Galerand (2008, p. 78) deixam - e que considero profundamente pertinente - ao movimento sindical e ao movimento feminista.

\section{Considerações finais}

A respeito da pertinência da análise combinada das teorias da sociologia das relações sociais de sexo e da psicodinâmica do trabalho: essa combinação permite ir além do lócus de análise que se ocupa, a partir da conceituação da divisão sexual 
do trabalho, em examinar o lugar ou as posições ocupadas por homens e mulheres no trabalho e suas diferentes formas de valoração, fornecendo também conceitos que permitem identificar e analisar as representações sociais e psíquicas da feminilidade e da virilidade no trabalho.

A referida pertinência parece se demonstrar tanto em trabalhos realizados eminentemente por homens como por mulheres, uma vez que falar em relações sociais de sexo ou de estratégias de defesa que mobilizem a virilidade ou feminilidade diz respeito aos trabalhos feitos por ambos. $\mathrm{O}$ argumento recobre, inclusive, situações de trabalhadores homens em postos de trabalho associados à feminilidade, ou o inverso, trabalhadoras em postos de trabalho associados à masculinidade.

Mas é a partir da análise dos trabalhos realizados eminentemente por mulheres que erigem os conceitos heuristicamente úteis para a análise das condições de trabalho e subjetividade desenvolvidos por Kergoat e por Molinier a respeito da "compaixão", do "autoescárnio" sobre a própria vulnerabilidade e da "luta contra a desvalorização do próprio trabalho", os quais seguem uma linha de continuidade argumentativa e que, portanto, merecem ser compreendidos de forma encadeada. Esses conceitos dizem respeito à investigação de um potencial não somente de defesas femininas contra o sofrimento no trabalho, mas de criação de vínculos entre as trabalhadoras e de uma transição de processos de defesa e de resistências individuais para práticas coletivas e reivindicativas sobre as condições de trabalho daquele coletivo.

Ademais, considero ser possível afirmar que o corpus teórico erigido das análises do trabalho de operárias e depois desenvolvido a partir da análise do trabalho das mulheres em setores eminentemente femininos como a enfermagem (e que por isso pode ter suas contribuições compreendidas como pertinentes apenas para analisar "trabalhos de cuidados") traz, em realidade, ferramentas analíticas para a observação da condição das mulheres no trabalho dentro da ampla variedade de profissões e atividades em que atuam.

Em tempos de agudização do individualismo e do concorrencialismo social no trabalho (LAVAL; DARDOT, 2016), a retomada do legado analítico que combina esses dois campos teóricos se mostra indispensável para retraçar e apontar as mediações necessárias a se compreender entre a atividade do trabalho real (acompanhado das estratégias de torná-lo "suportável") e a constituição de uma subjetividade atuante capaz de questionar e, por vezes, efetivamente agir para transformar os constrangimentos do trabalho.

Embora as autoras não conceituem as práticas no trabalho diretamente nesses temos, pode-se refletir, a partir de suas formulações, sobre o processo de 
conformação da solidariedade entre mulheres no trabalho (uma solidariedade ao mesmo tempo de classe e de sexo) como um fenômeno que, ao menos no aspecto potencial, se constitui em meio às relações intra e/ou extratrabalho assalariado. Esse processo de constituição de solidariedade entre mulheres no trabalho, portanto, é mais um elemento a considerar, além dos relativos à posição e valorização do trabalho (derivados dos princípios de separação e hierarquia da divisão sexual do trabalho) quando se analisa trabalho em seu sentido global assalariado e reprodutivo.

Tal legado teórico que aqui parcialmente recupero aponta para o caráter incontornável de compreender a classe trabalhadora feminina como dotada de práticas sociais que, por vezes, se diferem do que se consolidou como padrão "da classe", embora baseado em práticas masculinas que expressassem condutas viris.

Coletivos de trabalhadoras e suas práticas sociais de defesa podem se desenvolver a partir de "práticas insólitas" próprias, como o autoescárnio, o humor, a fantasia, sem contar as atitudes de compaixão entre trabalhadoras no ambiente da atividade profissional e os apoios mútuos entre trabalhadoras em questões de suas vidas que não estão exclusivamente ligados à atividade do espaço de trabalho assalariado. Ou seja, entre o trabalho real e a possibilidade de constituição da solidariedade entre trabalhadoras e/ou a constituição de coletivos de resistência, há muito mais mediações do que as costumeiramente levadas em consideração.

Observar tais mediações como conteúdo a ser tratado analiticamente, e não como práticas estereotipadas ou dramas pessoais "de mulheres" e não de trabalhadoras em seu sentido coletivo, parece ser um ótimo caminho para iniciar o processo de desbravar a compreensão, no feminino, dos processos de sofrimento, das defesas e resistências no trabalho.

\section{Referências}

APRE - Atelier Production/Reproduction.

(1988). Les rapports sociaux de sexe: problematiques, metodologies, champs d'analyses. Cahiers n. 7. vol. 1, 2 et 3, Paris.

DARDOT, Pierre; LAVAL, Christian.

(2016). A nova razão do mundo. Ensaio sobre a sociedade neoliberal. São Paulo, Boitempo.
DEJOURS, Cristophe.

(2012). Trabalho Vivo. Tomo 2. Trabalho e emancipação. Brasília, Editora Paralelo 15.

DEJOURS, Cristophe.

(1993). Inteligência operária e organização do trabalho: a propósito do modelo japonês de produção. In: HIRATA, Helena (org). Sobre o "modelo" japonês. São Paulo, Edusp. 
GALERAND, Elsa; KERGOAT, Danièle.

(2008). Le potentiel subversif du rapport des femmes au travail. Nouvelles questions féministes, vol. 27, n. 2, pp. 67-82.

HIRATA, Helena.

(2004). Trabalho doméstico: uma servidão voluntária? In: GODINH0, Tatau; SILVEIRA, Maria Lúcia. Políticas públicas e igualdade de gênero. Prefeitura de São Paulo - Coordenadoria Especial da Mulher, pp. 43-54.

HIRATA, Helena.

(1995). Relações sociais de sexo e do trabalho: contribuição à discussão sobre o conceito de Trabalho. Em Aberto, ano 15, n. 65. pp.38-49.

HIRATA, Helena; KERGOAT, Danièle.

(2008). Divisão sexual do trabalho profissional e doméstico: Brasil, França, Japão. In: COSTA, Albertina 0. et al. (orgs.). Mercado de Trabalho e Gênero: Comparações Internacionais. Rio de Janeiro, FGV.

HIRATA, Helena; KERGOAT, Danièle.

(2003). A divisão sexual do trabalho revisitada. In: MARUANI, Margaret; HIRATA, Helena (orgs.). As novas fronteiras da desigualdade: homens e mulheres no mercado de trabalho. São Paulo, SENAC.

HIRATA, Helena; KERGOAT, Danièle.

(2002). Relações sociais de sexo e psicopatologia do trabalho [1988]. In: HIRATA, Helena. Nova divisão sexual do trabalho? Um olhar voltado para a empresa e a sociedade. São Paulo, Boitempo.

KERGOAT, Danièle.

(2016). 0 cuidado e a imbricação das relações sociais. In: ABREU, Alice Rangel; HIRATA, Helena; LOMBARDI, Maria Rosa. Gênero e trabalho no Brasil e na França: perspectivas interseccionais. São Paulo, Boitempo.
KERGOAT, Danièle.

(2012). Se battre, disent-elles. Paris, La Dispute.

KERGOAT, Danièle.

(2010). Dinâmica e consubstancialidade das relações sociais. Revista Novos Estudos, n. 86, pp. 93-103.

KERGOAT, Danièle.

(2001). Le syllogisme de la constitution du sujet sexué féminin. Le cas des ouvrières spécialisées[1987]. Travailler, vol. 2, n. 6, pp. 105-114.

MOLINIER, Pascale.

(2013). 0 Trabalho e a Psique. Uma Introdução à Psicodinâmica do Trabalho. Brasília, Editora Paralelo 15.

MOLINIER, Pascale.

(2006). L'énigme de la femme active. Égoisme, sexe et compassion. Paris, Payot.

MOLINIER, Pascale.

(2004). 0 ódio e o amor, caixa preta do feminismo? Uma crítica da ética do devotamento. Psicologia em Revista, v. 10, n. 16, pp. 227-242.

\section{Recebido em}

março de 2019

\section{Aprovado em}

abril de 2020 